\title{
Information Feedback Between Size Portfolios in Boursa Kuwait
}

\author{
Saad Alhajraf ${ }^{1}$ \\ ${ }^{1}$ Alhajraf Investment Company, Kuwait \\ Correspondence: Saad Alhajraf, Alhajraf Investment Company, Kuwait.
}

Received: March 7, 2021; Accepted: March 22, 2021; Published: March 26, 2021

\begin{abstract}
This paper examines the transmission of information between small and large sized portfolios within the Boursa Kuwait between 2011 and 2020. The study documents a constant and steady stream of feedback which demonstrates a sizeable and significant impact on market volatility; albeit at varying degrees of effect on smaller portfolios as compared with larger ones. Evidence suggests a more persistent volatility on larger portfolios, indicating a disparity on the interpretations of transmitted information between the varied styles of investors in the Kuwait Boursa.
\end{abstract}

Keywords: portfolios, information feedback, Kuwait, market volatility, financial markets

\section{Introduction}

Transmission of information has attracted finance academics through many studies of financial markets interdependence, however, information feedback in the context of portfolio allocation is still lagging in terms of the quantity of research. The importance of this issue comes from the fact that the transmission of information between different portfolio sizes has strong implications to portfolio construction as investors always seek to maximize their portfolios' expected returns by estimating the optimal allocation of their investments.

Whilst many studies have sought to understand market independence and extensively covered transmission of information as a factor; information feedback in the context of portfolio allocation remains scarce by comparison and lags behind in terms of both quality and quantity of research. This remains the case despite holding significant implications to portfolio construction and management with investors seeking optimal allocations of their investments on the basis of expected returns with a view to maximizing these returns.

One important metric for investors is cross-correlation of stocks, usually examined by employing GARCH specifications in order to account for information spillover to the conditional correlation between different stocks whilst also enabling researchers to explore multidirectional information transmission between stock returns. Information feedback between large and small portfolios takes added significance given its notable impact on expected returns on the investors' respective portfolios. Such information also has a profound impact on decisionmaking in reference to period reallocations and rebalancing of portfolios.

Indeed, many empirical papers covering this area of research assume that investors will typically adopt conventional, mean-variance optimization strategies designed to maximise expected returns within their respective risk appetites.

More specifically, when identifying the effects of information feedback on Boursa Kuwait, we can draw parallels with previous studies demonstrating its impact in other markets with larger data sets. Ross (1989) for example linked information flow to volatility, particularly in the case of smaller firms whose returns tend to lag behind larger ones. Similarly, Lo and Mackinlay (1990) found evidence that stock prices changes of larger stocks often preceded those of smaller stocks.

The relationship between volatility and the size of a portfolio was also investigated by Conrad et al (1991), which found an asymmetric effect of transmission of volatility with volatility appearing to transmit from larger firms to smaller ones, but not vice versa

McQueen et al (1996) seem to support the previous findings, going on to document significant asymmetry in cross correlation in US stock portfolios of various sizes. Grieb and Reyes (2002) meanwhile, investigate the volatility spillover between large and small stock returns in UK stocks; seemingly confirming persistent correlation between the two size-based indices with a more consistent two-way flow of information. 
The above studies however, have relied on significantly more developed markets than the Boursa Kuwait, especially in terms of settlement procedures. Many of the standard models used in modern finance are however, in their current forms, ill-suited to account for many of the circumstances and idiosyncrasies specific to emerging markets.

As suggested by Bekaert and Harvey (2003), an opportunity arises therefore, for finance models to be amended, modified, updated or completely redesigned in order to accommodate the structure and trading patterns of emerging markets such as the Boursa Kuwait, in order to take on added relevance in a quickly developing global scene

Given the above, it is the following hypotheses that this study seeks to investigate:

(H1): There is no feedback effect between large and small size portfolio returns

(H2): Returns of small and large portfolios are not correlated

\section{Data}

This study uses daily closing index values that span the period 3-Jan-2012 to 31-Dec 2020 with total sample daily observations of 2367. The index used is constructed by the Global Investment House (a prestigious investment and brokerage firm in Kuwait) and is capitalization weighted index which avoids the bias introduced by value weighted indices. The index includes all firms traded in Boursa Kuwait.

\section{Methodology}

To account for constant parameterization, all returns are calculated by taking the log of the previous day's index value divided by today's index value as follows

$$
\mathrm{R}_{\mathrm{it}}=\ln \left\{\mathrm{R}_{\mathrm{it}} / \mathrm{R}_{\mathrm{it}-1}\right\}
$$

For the purpose of this study, two indices are used. The large index portfolio (LI) includes the largest 10 firms in terms of market value with monthly rebalancing while the small index portfolio (SI) includes the smallest 10 firms in terms of market values and is also with monthly rebalancing. Portfolios are formed at the beginning of each month based on the firms' market values and held for one month.

As in Hamao et al (1990) and Booth et al (1997), this paper employs the Exponential generalized Autoregressive Conditional Hetroscedasticity (EGARCH) framework in order to investigate any information spillover between the large and small capitalization stocks in Boursa Kuwait. Koutmos (1996) also examined the information transmission among several financial markets by employing the GARCH framework in order to account for hetreoscedasticity and any possible interactions among markets. Others, such as Darber and Deb (1997), Longin and Solink (1995), King et al (1994), Darbar and Deb (1999, 2000), and Deb (2000) investigated the cross correlation and information spillovers among many financial markets. With this study focusing on micro level factors of financial markets, as it strives to find evidence of time-varying correlation between stocks of contrasting capitalizations, the EGARCH model is perfectly suited as it divulges a two-way information flow between large and small capitalization portfolios to the next period's correlation.

The specification of the EGARCH model employed in this study is in line with the the original specification proposed by Nelson (1991), which uses the assumption that the conditional variance of stock returns as a function both; its lagged innovation and the lagged conditional variance. The original specification of Nelson (1991) that is employed in this study is as follows:

$$
\begin{array}{r}
\mathrm{R}_{\mathrm{it}}=\mathrm{f}\left\{\mathrm{R}_{\mathrm{it}-1}, \mathrm{R}_{\mathrm{jt}}, \mathrm{R}_{\mathrm{jt}-1},\right\} \\
\log \left(\sigma_{t}^{2}\right)=\omega+\beta \log \left(\sigma_{t-1}^{2}\right)+\alpha\left|\frac{\varepsilon_{t-1}}{\sigma_{t-1}}\right|+\gamma \frac{\varepsilon_{t-1}}{\sigma_{t-1}}
\end{array}
$$

Where, in equation (1), " $\mathrm{R}_{\mathrm{it}}$ " $\left(\mathrm{R}_{\mathrm{j} t}\right)$ stands for returns of the large (small) portfolio returns. The same equation is run for the small portfolio returns. The second equation models the log of the conditional variance where the leverage effect is exponential which means that the forecasts of the conditional variance will be non-negative.

In order to corroborate results, the feedback effect is also detected through a set of linear equations that include different variables whose effects are expected to be significant and hence show any potential contemporaneous spillover between the two sets of portfolio returns. The parameterization of the "seemingly unrelated regression" (SUR) takes the following form

$$
\mathrm{R}_{\mathrm{it}}=\mathrm{f}\left\{\mathrm{R}_{\mathrm{it}}, \mathrm{R}_{\mathrm{it}-1}, \operatorname{Corr}_{\mathrm{t}-1}, \mathrm{SD}\left(\mathrm{R}_{\mathrm{it}}\right)\right\}
$$


where " $\mathrm{R}_{\mathrm{it}}$ " denotes the returns of large $(\mathrm{RL})$ size portfolio. The same equation is run for the small (RS) size portfolio. The explanatory variables test any contemporaneous feedback between the two portfolio returns. The "Corr $\mathrm{t}_{-1}$ " is the time-varying one-period lagged correlation between the two portfolio returns while the " $\mathrm{SD}($.$) "$ refers to the time-varying risk of the two portfolios.

Table 1 reports the results of a preliminary examination of the data which includes the basic statistics and correlation

Table 1. Summary Statistics of the Portfolio Returns

\begin{tabular}{llll}
\hline & GI & LI & SI \\
\hline Mean & 0.0003 & 0.003 & 0.002 \\
\hline Standard Deviation & 0.0037 & 0.0056 & 0.0116 \\
\hline Skew & 0.563 & 0.16 & -0.148 \\
\hline Kurt & 18.06 & 5.36 & 8.16 \\
\hline Jarque-Bera test for normality & & 2547 & 7981 \\
& & $(0.0001)$ & $(0.0001)$ \\
\hline Corr (LI,SI) & .34 & & \\
\hline Prob of Q-stat (lags $1|10| 30)$ & & $0.023|0.001| 0.001$ & $0.001|0.001| 0.001$ \\
\hline
\end{tabular}

The table indicates that the mean return is the highest for the small size portfolio which conforms to the literature of the small-size effect. The risk is also higher for the small-size portfolio which also comes in line with results obtained in the literature, such as that of Black (1986). Return distributions for both portfolios are seen to be abnormal as evidenced by the Jarque-Bera test for normality. The small-size portfolio returns are skewed to the left, whilst the larger portfolios are skewed to the right. The autocorrelation test of lags up to thirty (30) days indicates that the two series of returns show evidence of strong dependence and strong ARCH effect which must be tested formally and accounted for within the analyses

\section{Results}

Given this papers intention to investigate the presence of returns of large-size portfolios as compared with smallersized ones in Boursa Kuwait, table 2 contains the effect of the lagged value of "RS" and "RL" on "RS" using the EGARCH specification. Results in the table show that, unlike the lagged values of "RS" with relation to "RS", the effect of the lagged value of "RL" on "RL" is insignificant; i.e. the autoregressive term is insignificant. However, the autoregressive term of "RS" significantly affects the "RL". The EGARGH coefficient is significantly different from zero which confirms the significance of the GARCH effect. This partially confirms the results of Grieb and Reyes of UK size-based stock portfolios as their results document a significant autoregressive term in both large and small index returns. Moreover, as far as this parameterization is concerned, the results of the analysis show that the leverage effect exists for the "RL" model. On the other hand, the results are seen to differ for the "RS" portfolio. The lagged values of both the "RL" and "RS" have significant effect upon the "RS". This result contradicts the no-spillover effect documented by Reyes (2001) when studying the Tokyo stock exchange. The past volatility also effects the "RS" portfolio at the $1 \%$ level. In addition, the asymmetric volatility is statistically apparent in the data which confirms the leverage effect of Black (1986) and supports Reyes (2001) for Japanese stocks. Whilst the coefficient estimates for both models suggest a high volatility persistence, these estimates imply that volatility shocks to the returns on small-size portfolios persist longer than such shocks to the larger-sized portfolios; a results that comes in line with the implication of the evidence documented by Grieb and Reyes (2002) and McQueen et all (1996). More specifically, whilst about 73.2\% of a certain shock is seen to remain after 3 days for returns of the small-size portfolios $(=.9011)$, only about $36.6 \%$ of the same shock remains for the same 3-day period of larger-sized portfolios.

Taken together, these results confirm the feedback effect between the two portfolio returns. Since the model describes historical portfolio behavior, it would appear that informative investors on Bourse Kuwait, who construct portfolios using size criteria (most likely the institutional investors), reshuffle their portfolios based on information from different sources and from these are the returns variations of both small and large portfolios. 
Table 2. The Effect of Lagged Values of Size Portfolios

\begin{tabular}{lll}
\hline Dep. Var. & RL & RS \\
\hline RL (-1) & .0462 & .0722 \\
& $(.1123)$ & $(.0003)$ \\
\hline RS (-1) & .0374 & .1618 \\
& $(.0512)$ & $(.0001)$ \\
\hline \multicolumn{3}{l}{ The Variance Equation } \\
\hline$\omega$ & -2.8997 & -1.1368 \\
& $(.059)$ & $(.0007)$ \\
\hline$\beta$ & .1705 & .2415 \\
& $(.0733)$ & $(.0001)$ \\
\hline$\alpha$ & .0442 & .0567 \\
& $(.4351)$ & $(.1364)$ \\
\hline$\gamma$ & .7154 & .9011 \\
& $(.0001)$ & $(.0001)$ \\
\hline Adj. R-square & .000016 & .0323 \\
\hline
\end{tabular}

In order to further explore any feedback effect between the large and the small-size portfolios, as well as to corroborate the results obtained in the EGARCH test, an unrelated regression (SUR) model is developed to investigate any contemporaneous effect from the many exogenous factors that are not considered in the study. The conjecture here is that since both portfolios are from the same market, they should suffer similarly from any external shocks that have not been considered in the analysis. That is, disturbances in the different equations at a given time are likely to reflect some common measurable or omitted factors, and hence could be contemporaneously correlated.

Table 3 shows the results of the SUR model where the two variables, the "RL" and the "RS" are modeled as a function of some control variables. Many models have been run and the results are consistent. The results of model 1 show that the returns of the "RS" portfolio have significant effect on the returns of the "RL" portfolios. Even if the lagged values of the "RS" returns are considered, we still observe a significant effect on the large portfolio returns. The implication is clear: there is a feedback effect between the large and small size portfolio returns in Boursa Kuwait. As for the lagged correlation between the returns of the two portfolios, it also has its significant effect upon the returns of both portfolios. However, that effect is not symmetrical. Specifically, while the lagged correlation has negative and significant effect on the "RL", it has a positive and statistically significant effect on the "RS".

Table 3. SUR Model of the "RS" and "RL" Portfolios

\begin{tabular}{lllllll}
\hline Dep. & $(1)$ & $(2)$ & $(3)$ & $(4)$ & $(5)$ & $(6)$ \\
Var. & $\mathrm{RL}$ & $\mathrm{RL}$ & $\mathrm{RL}$ & $\mathrm{RS}$ & $\mathrm{RS}$ & $\mathrm{RS}$ \\
\hline Intercept & -.0003 & 0004 & .0006 & .0008 & .0007 & .0002 \\
& $(.2268)$ & $(.0377)$ & $(.2566)$ & $(.0052)$ & $(.001)$ & $(.8106)$ \\
\hline $\mathrm{RL}$ & & & .7316 & & .7335 \\
& & & $(.0001)$ & & $(.0001)$ \\
\hline RL(-1) & .0117 & .0366 & .0095 & .0227 & .0483 & .025 \\
& $(.5693)$ & $(.0921)$ & $(.6432)$ & $(.3611)$ & $(.0676)$ & $(.3161)$ \\
\hline RS & .4958 & & .697 & & & \\
& $(.0001)$ & & $.0001)$ & & & .1744 \\
\hline RS(-1) & -.0603 & .0247 & -.0588 & .1546 & .1523 \\
& $(.0003)$ & $(.1614)$ & $(.0005)$ & $(.0001)$ & $(.0001)$ & $(.0001)$ \\
\hline Corr (-1) & .0012 & & .002 & -.0014 & & -.003 \\
& $(.0759)$ & & $(.006)$ & $(.0713)$ & & $(.0044)$
\end{tabular}




\begin{tabular}{|c|c|c|c|c|c|c|}
\hline $\mathrm{SD}(\mathrm{Rl})$ & & & $\begin{array}{l}-.0433 \\
(.4863) \\
\end{array}$ & & & $\begin{array}{l}.0178 \\
(.8135) \\
\end{array}$ \\
\hline SD (RS) & & & $\begin{array}{l}-.0786 \\
(.0406)\end{array}$ & & & $\begin{array}{l}.0874 \\
(.0609) \\
\end{array}$ \\
\hline OBS & 2366 & 2366 & 2366 & 2366 & 2366 & 2366 \\
\hline Adj. R-Sq. & .04 & .002 & .04 & .07 & .04 & .08 \\
\hline
\end{tabular}

The same is correct when considering the contemporaneous correlation (results are not shown). Although this result demonstrates that correlation is an important piece of information that can be used to improve the performance of Kuwaiti investors' portfolios, the inconsistency in the effect of the correlation on both portfolios could be an indicator of a noise in investment trading during the studied period. Furthermore, this result may lead to the formation of a style of portfolio management for investors in Boursa Kuwait. Model (2) tests only the effect of the lagged values of both "RS" and "RL". The results are not different from those obtained in table 2 when considering the $5 \%$ significance level as both lagged values have no significant effect on the "RL". This model, thought, has less predicting power than model (1). To corroborate the results of model (1), model (3) employs the same variables but adds the return volatility of both portfolios. The results show that this model has the same predicting power as model (1) and all variables retain their sign. The return variability of the "RS" significantly and negatively affects "RL" while the return variability of "RL" has no significant effect on the "RL" returns. This result seems eccentric since it is expected that the volatility of "RL" would affect large stock returns. The results also contradict Lo and MacKinlay (1990) who document asymmetric cross-autocorrelation between size-based portfolios of the US stock market.

Models (4), (5), and (6) relate to the determinants of "RS" returns employing the same proposed variables thought to affect "RL" returns. The results of model (4) show that the information about both the "RL" returns and the one period lagged returns of "RS" have positive effect on the "RS" portfolio returns. One may surmise form this that Kuwaiti investors use this information to make their investment decisions during the alteration of the assets in their portfolio. The one-period lagged correlation, whilst it shows a positive effect on the "RL" returns, negatively affects the "RS" returns (considering a 10\% significance level). Model (5) replicates the analysis in model (4) and the results are the same to those that are obtained in table 2 in terms of the positive effect of the lagged value of both the "RL" returns and the "RS" returns upon the "RS" returns. Model (6) is analogous to model (3) of "RL" returns in terms of the included variables. The results of this model again show that the return variability of "RL" has no significant effect on the "RS" return. However, "RS" returns' variability has a positive effect on the "RS" portfolios returns. The reason appears clear from the results in table 2 which show that the volatility persistence of "RS" is higher than that of "RL" and hence its effect would expectedly be higher and more considered by investors in Boursa Kuwait. This would suggest that investors in Boursa Kuwait tend to place a higher value on information related to "RS" more than they do for those related to "RL". This contention is supported by the fact that the predictive power of model (6), as well as model (4), is the highest of those studied.

\section{Conclusion}

This study provides evidence of a feedback effect between returns of large and small portfolios in Kuwait' stock exchange (Boursa Kuwait). The findings appear to support the hypotheses of $t$ information flow from one period to the next as the correlation between returns of the smaller and larger sized portfolios affect the returns in the following period for both sets of portfolios; albeit to varying degrees. The existence of this effect may primarily be caused by the continuous arrival of information which, in theory, should impact all stocks across the Boursa Kuwait; a fact that is by and large supported by the literature.

It might also be the volatility changes that lead investors towards a shift in focus from one market to another (King and Wadhawani, 1990). Specifically, a volatility persistence was detected, and that persistence lasts longer for the small-size portfolio than for the large-size ones. The difference in the effect on both portfolios implies that what is considered good news for small stocks may be considered bad news for larger ones. In other words, the study documents a sensitivity of changes in returns due to the explanatory factors considered and contained within this study. This sensitivity appears to support the conjecture that investors usually infer that the nonfundamental factors that affect both large and small firms within the economy are different; and therefore, potentially manifests in varied decision making by investors when making their investment decisions based on small and large stock fundamentals. Generally speaking, the results of this study suggest that studies of portfolio selections and investment behavior in Boursa Kuwait should account for both the contemporaneous and the one-period lagged 
volatility effect. additionally, this study supports the well-documented and long-observed leverage effect of stock returns where there is an asymmetric effect on volatility during rising and falling stock markets.

\section{References}

Bekaert, G., \& Harvey, C. (2003). Emerging Markets Finance. Journal of Empirical Finance, V(10), 3-55. https://doi.org/10.1016/S0927-5398(02)00054-3

Black, F. (1986). "Noise". Journal of Finance, V(41), 529-543. https://doi.org/10.1111/j.15406261.1986.tb04513.x

Booth, G., Martikainen, T., \& Tse, Y. (1997). Price and Volatility Spillovers in Scandinavian Stock Markets. Journal of Banking and Finance, V(21), 811-823. https://doi.org/10.1016/S0378-4266(97)00006-X

Butler, K., \& Malaikah, S. (1992). Efficiency and Inefficiency in Thinly Traded Stock Market: Kuwait and Saudi Arabia. Journal of Banking and Finance, V(16), 197-210. https://doi.org/10.1016/0378-4266(92)90085-E

Darbar, S., \& Deb, P. (1997). Co-Movements in International Equity markets. Journal of Financial Research, $\mathrm{V}(20), 305-322$. https://doi.org/10.1111/j.1475-6803.1997.tb00251.x

Darbar, S., \& Deb, P. (1990). Linkage Among Asset markets in The united States-tests in a Bivariate GARCH Framework. IMF Working Paper \# 99/158.

Darbar, S., \& Deb, P. (2000). Transmission of Information and Cross-market Correlation. Working paper, Indiana University and Purdue University, Indianapolis.

Grieb, T., \& Mario, R. (2002). The Temporal relationship Between large and Small Capitalization Stock Returns: Evidence from the UK. Review of Financial Economics, V(11), 109-118. https://doi.org/10.1016/S10590560(02)00104-1

Hamao, Y., Masulis, R., \& Ng, V. (1990). The Effects of the Stock Markets Crash on Financial Integration”, Review of Financial Studies, V(3), 281-307. https://doi.org/10.1093/rfs/3.2.281

King, M., \& Wadhawani, S. (1990). Transmission of Volatility Between Stock markets. Review of Financial Studies, V(3), 5-33. https://doi.org/10.1093/rfs/3.1.5

Koutmos, G. (1996). Modeling the dynamic Interdependence of Major European Stock Markets. Journal of Business Finance and Accounting, V(23), 975-988. https://doi.org/10.1111/j.1468-5957.1996.tb01035.x

Lo, A., \& MacKinlay, C. (1990). When are Contrarian Profits due to Stock Market Over Reaction”, Review of Financial Studies, V(3), 175-205. https://doi.org/10.1093/rfs/3.2.175

Longin, F., \& Solnik, B. (1995). Is the Correlation in International Equity Returns Constant: 1960-1990?”, Journal of International Money and Finance, V(14), 3-26. https://doi.org/10.1016/0261-5606(94)00001-H

McQueen, G., Pinegar, M., \& Thorely, S. (1996). Delayed Reaction to Good News and the Cross Autocorrelation of portfolio Returns, Journal of Finance, V(51), 889-919. https://doi.org/10.1111/j.15406261.1996.tb02711.x

\section{Copyrights}

Copyright for this article is retained by the author(s), with first publication rights granted to the journal.

This is an open-access article distributed under the terms and conditions of the Creative Commons Attribution license (http://creativecommons.org/licenses/by/4.0/). 